\title{
Monitoring Cerebral and Renal Oxygenation Status during Neonatal Digestive Surgeries Using Near Infrared Spectroscopy
}

\author{
Jonathan Beck ${ }^{1 *}$, Gauthier Loron ${ }^{1}$, Claire Masson ${ }^{2}$, Marie-Laurence Poli-Merol ${ }^{3,4}$, \\ Eliane Guyot ${ }^{5}$, Camille Guillot ${ }^{6}$, Nathalie Bednarek ${ }^{1,4}$ and Caroline François ${ }^{7,8}$
}

${ }^{1}$ Neonatal and Pediatric Intensive Care Unit, CHU of Reims American Memorial Hospital, Reims, France, ${ }^{2}$ Department of Research and Public Health, CHU of Reims, Reims, France, ${ }^{3}$ Department of Pediatric Surgery, $\mathrm{CHU}$ of Reims Hôpital Maison Blanche, Reims, France, ${ }^{4}$ University of Reims Champagne Ardennes, UFR médecine, Reims, France, ${ }^{5}$ Department of Pediatric Anesthesia, CHU of Reims Hôpital Maison Blanche, Reims, France, ${ }^{6}$ Pediatric Intensive Care Unit, CHRU of Lille, Lille, France, ${ }^{7}$ Plastic Reconstructive Surgery and Anesthesiology, CHU of Reims Hôpital Maison Blanche, Reims, France, ${ }^{8}$ EA 3801 Laboratory, Champagne Ardennes University SFR CAP santé Reims-Amiens, UFR médecine, Reims, France

OPEN ACCESS

Edited by:

Juan A. Tovar

Hospital Universitario La Paz,

Spain

Reviewed by:

Andrea Conforti,

Bambino Gesù Ospedale

Pediatrico (IRCCS), Italy

Francesco Morini,

Bambino Gesù Ospedale

Pediatrico (IRCCS), Italy

*Correspondence:

Jonathan Beck

becki1187@gmail.com

Specialty section:

This article was submitted to

Pediatric Surgery,

a section of the journal

Frontiers in Pediatrics

Received: 03 January 2017 Accepted: 01 June 2017

Published: 14 June 2017

Citation:

Beck J, Loron G, Masson C, Poli-Merol M-L, Guyot E, Guillot C, Bednarek N and François C (2017)

Monitoring Cerebral and Renal

Oxygenation Status during Neonatal

Digestive Surgeries Using Near

Infrared Spectroscopy.

Front. Pediatr. 5:140.

doi: 10.3389/fped.2017.00140
Background: Depending on the initial pathology, hypovolemia, intra-abdominal hypertension, and sepsis are often encountered in neonatal digestive surgery. Accurate newborn monitoring during and after surgery is essential to adapt resuscitation protocols. Near infrared spectroscopy (NIRS) is non-invasive and can detect hypoperfusion which indicates a low circulatory blood flow, regardless of the cause.

Objective: Evaluating changes in cerebral and renal regional oxygen saturation during neonatal digestive surgeries, conducted according to normal practices, with commonly used monitoring parameters. Analyzing retrospectively the inter-relationships between NIRS values and mean arterial pressure (MAP) values as well as pre-ductal $\mathrm{SpO}_{2}$.

Methods: Prospective, descriptive, monocentric study. All neonates referred for surgery were included. NIRS allows the measurement of cerebral and renal oxygenation fluctuations, as well as calculating difference in intraoperative and postoperative values.

Results: Nineteen patients were included. Cerebral regional oxygen saturation $\left(\mathrm{C} \mathrm{rSO}_{2}\right)$ values were stable while renal regional oxygen saturation $\left(\mathrm{R} \mathrm{rSO}_{2}\right)$ values tended to decrease with time during surgery. Indeed, $72 \%$ of $\mathrm{rSO}_{2}$ decline episodes occurred after the first 30 min of surgery, without any significant statistical differences for the next 90 min of surgery. After surgery, the lowest average $\mathrm{C}$ and $\mathrm{R} \mathrm{rSO}_{2}$ values were evidenced during the first $6 \mathrm{~h}$, with $60 \%$ of $\mathrm{C} \mathrm{rSO}_{2}$ and $\mathrm{R} \mathrm{rSO}_{2}$ anomalies occurring in that time frame. There was no significant statistical difference observed in the following $18 \mathrm{~h}$. There was a significant correlation between $\mathrm{R} \mathrm{rSO}$ and $\mathrm{SpO}_{2}$ values $\left(p<0.01\right.$ ), but not with $\mathrm{CrSO}_{2}$ values. There was no correlation with the MAP either for the $\mathrm{C} \mathrm{rSO}_{2}$ values or $\mathrm{R} \mathrm{rSO}$ ones.

Conclusion: NIRS is a promising non-invasive bedside tool to monitor cerebral and tissue perfusion, analyzing tissue microcirculation. NIRS has its interest to guide neonatal digestive surgeries (bowel manipulation, viscera reduction) and may represent an early warning for identifying patients requiring resuscitation during or after these surgeries.

Keywords: NIRS, neonatal surgery, neonatal anesthesia, neonatal monitoring, abdominal compartment syndrome, Intraoperative monitoring, hypovolemia 


\section{INTRODUCTION}

Neonatal digestive surgery, whether to correct a malformation [gastroschisis, omphalocele, congenital diaphragmatic hernia $(\mathrm{CDH})$, or esophageal atresia (EA)] or an acquired pathology such as necrotizing enterocolitis (NEC) can pose a lifethreatening risk for these children. Whether a consequence of the anesthesia (vasodilatation, hypovolemia, bradycardia), or of the surgery itself (bleeding, loss of bodily fluids, hypothermia), or of related procedures to the initial pathology (reintegration of herniated viscera within the abdomen, sepsis, thoracotomy, and lateral decubitus), a monitoring of the circulatory and ventilatory statuses is mandatory in such cases (1-3).

The neonatal team needs to anticipate these adverse events. To date, only systemic measures are available such as fluid volume evaluation and blood flow status.

Fluid volume is monitored before, during, and after surgery by direct and indirect mean arterial pressure (MAP in $\mathrm{mmHg}$ ) and heart rate (HR in beats per min) measurements. Ventilation status is documented by pre- or post-ductal pulse oximetry $\left(\mathrm{SpO}_{2}\right.$ in\%), arterial oxygen tension $\left(\mathrm{PaO}_{2}\right.$ in $\left.\mathrm{mmHg}\right)$, expiratory or peak inspiratory pressure (PIP in $\mathrm{cmH}_{2} \mathrm{O}$ ), fraction of inspired oxygen $\left(\mathrm{FiO}_{2}\right.$ in\%), and measurement of end tidal $\mathrm{CO}_{2}$ tension $\left(\mathrm{EtPCO}_{2}\right.$ in $\left.\mathrm{mmHg}\right)$, via transcutaneous $\left(\mathrm{TcPCO}_{2}\right.$ in $\mathrm{mmHg}$ ) or blood $\left(\mathrm{PCO}_{2} \mathrm{~b}\right.$ in $\mathrm{mmHg}$ ) measures $(4,5)$.

When abdominal compartment syndrome might be an adverse event, especially in surgery for anterior abdominal wall closure anomalies, an intra-abdominal pressure (iaP) measure could be useful. Intra-abdominal hypertension, defined by iaP $>12 \mathrm{mmHg}$ (6), increases the ventilatory and circulatory risks on these fragile newborns. Even if this progressive approach, consisting in placing a silo pouch stoma to contain the viscera, it is often used when the neonate's state is quite frail, there is no validated standard method for iaP measure in neonatal surgery (7).

Similarly, no method has been validated to assess perfusion and oxygenation quality of the different viscera during or after neonatal digestive surgeries $(4,5)$.

It seems essential to develop more precise regional monitoring of tissue perfusion and oxygenation, allowing early detection of adverse circulatory or ventilation events for implementing a better therapeutic response. Near infrared spectroscopy (NIRS) might have this potential in neonatal digestive surgeries.

Near infrared spectroscopy was first reported in 1977 by Jobsis as a continuous non-invasive technique measuring tissue oxygenation. Regional oxygen saturation $\left(\mathrm{rSO}_{2}\right)$ reflects the

\footnotetext{
Abbreviations: ACS, abdominal compartment syndrome; BW, birth weight; $\mathrm{C}$, cerebral; $\mathrm{CDH}$, congenital diaphragmatic hernia; $\mathrm{CO}_{2}$, carbon dioxide measurement; EDIN, scale of pain and discomfort of the new-born; EA, esophageal atresia; $\mathrm{EtCO}_{2}$, exhaled carbon dioxide measurement; FDA, food and drug administration; $\mathrm{FiO}_{2}$, fraction of inspirated oxygen; FM, fluid management; $\mathrm{HHb}$, deoxyhemoglobin; $\mathrm{HbO}_{2}$, oxy-hemoglobin; $\mathrm{HR}$, heart rate; iaP, intra-abdominal pressure; $\mathrm{IQR}$, interquartile ratio; IRB, institutional review board; $\mathrm{m}$, min; MAP, mean arterial pressure; NEC, necrotizing enterocolitis; NICU, neonatal intensive care unit; NIRS, near infrared spectroscopy; $\mathrm{PCO}_{2}$ b, blood carbon dioxide measurement; PIP, peak inspiratory pressure; $\mathrm{R}$, renal; $\mathrm{rSO}_{2}$, regional tissue oxygen saturation; $\mathrm{SaO}_{2}$, arterial oxygen saturation; $\mathrm{SpO}_{2}$, oxygen saturation; $\mathrm{TcPCO}_{2}$, transcutaneous carbon dioxide measurement; WA, weeks of amenorrhea.
}

balance between the tissues' oxygen requirements and actual tissue oxygenation. It also reflects the microcirculation of arterial, venous, and capillary networks: $75-85 \%$ of the signal comes from venules (8-11). NIRS is interesting for detecting subclinical hypoperfusion (microcirculatory dysfunctions).

Analyzing $\mathrm{rSO}_{2}$ variations can assess perfusion quality in an area of interest. Many studies focused on cerebral perfusion during cardiac and vascular surgeries (12).

Little is known about the relevance of NIRS in the simultaneous monitoring of cerebral and abdominal or renal perfusion in neonatal digestive surgeries (13-16). Giliberti et al. reported and summarized the results of a study on the application of NIRS in neonatal cardiac and digestive surgeries, on its future possibilities and its relevance on perfusion and oxygenation monitoring during these surgeries and during anesthesia.

In this work, the objective was to study the NIRS renal and cerebral parameters variation during and after classic digestive neonatal surgical procedures, describing pathological $\mathrm{rSO}_{2}$ during and after surgeries, as well as associated events and these parameters' behavior during fluid management (FM).

A secondary objective was to analyze correlations between NIRS parameters, MAP, and pre-ductal $\mathrm{SpO}_{2}$ values.

\section{MATERIALS AND METHODS}

\section{Subjects}

Each neonate admitted in the neonatal intensive care unit (NICU), from October 2014 to November 2015, for a surgical digestive procedure (gastroschisis, omphalocele, $\mathrm{CDH}, \mathrm{EA}, \mathrm{NEC}$, neonatal bowel obstruction, abdominal tumor) was included in the study. Neonates who died before surgery and/or had a medically managed NEC were excluded. All patients included had general anesthesia during the procedure. The study was approved by the local ethics committee of the Reims Teaching University Hospital, and all parents received full disclosure on this study and the procedure.

\section{Hemodynamic and Respiratory Parameters Measurement and Analysis}

Mean arterial pressure, $\mathrm{HR}$, and pre-ductal $\mathrm{SpO}_{2}$ were measured with the monitor IntelliVue MX700 (Philips Healthcare, Allmendstrasse 140, 8027 Zürich, Switzerland) associated with its multi-measures module which connected a Massimo set for $\mathrm{SpO}_{2}$. These non-invasive techniques adapted to age and weight. All monitoring equipment was calibrated according to manufacturer's standards.

The hemodynamic and respiratory monitoring started at the newborn admission. During and after surgery, $\mathrm{HR}$ and $\mathrm{SpO}_{2}$ were continuously measured. During surgery, parameters' values were recorded every $15 \mathrm{~min}$ by the health-care team. Postoperative, values were recorded every hour during the first $6 h$, then every 3 h. Post-ductal $\mathrm{SpO}_{2}$ values of the lower limbs were only a recorded with pre-ductal $\mathrm{SpO}_{2}$ values during herniated viscera reintegration surgery (gastroschisis, omphalocele, and $\mathrm{CDH}$ ).

Mean arterial pressure was measured and recorded every $15 \mathrm{~min}$ in intraoperative and every hour in postoperative during the first $6 \mathrm{~h}$, then every $3 \mathrm{~h}$. 
During anesthesia and surgery, $\mathrm{FiO}_{2}$ values were systematically greater than $60 \%$ and PIP between 18 and $22 \mathrm{mmHg}$. The patients were mechanically ventilated by tracheal tube with a pressure controlled ventilation mode.

\section{NIRS Measurement and Analysis}

Near infrared spectroscopy measurements were performed using a continuous wave system (INVOS 5100C, Somanetics, Troy, MI, USA), used the two-channel mode, with channel 1 for cerebral monitoring and channel 2 for somatic/renal monitoring. One Cerebral/Somatic oximetry Infant-Neonatal sensor (Somanetics, Troy, MI, USA), made of an emitting diode and two detectors, was used on channel 1 and one on channel 2 during this study.

The continuous wave NIRS system uses the properties of luminous absorption of photons going through the tissues by two different wavelengths (730 and $810 \mathrm{~nm}$ ), both used in this study. Light travels from the sensor's light emitting diode to either a proximal or distal detector, permitting separate data processing of shallow and deep optical signals. Relative changes in the absorption of near-infrared light were sampled at $10 \mathrm{~Hz}$, and these values were converted to changes in the concentration of oxy-hemoglobin $\left(\mathrm{HbO}_{2}\right)$ and deoxy-hemoglobin ( $\mathrm{HHb}$ ) based on the modified Beer-Lambert approach to obtain $\mathrm{rSO}_{2}$ values, according to the formula $\mathrm{rSO}_{2}=\mathrm{HbO}_{2} /\left(\mathrm{HbO}_{2}+\mathrm{HHb}\right)$.

The sensors can be placed on several parts of the body, above the organs of interest $(8,9)$. We used a cerebral $(C)$ sensor which was positioned on the forehead (below the hairline) and a renal (R) sensor on the neonate's lower back (right side) between T10 and L2, 30 min before leaving for the operating room, when the surgery was an emergency the sensors were positioned in the operating room. Cerebral and renal $\mathrm{rSO}_{2}$ values were continuously recorded. In the operating room, before setting up, the surgeons checked the position of the sensor and consolidated its fixation. The anesthetists made sure of uninterrupted recording.

We defined an initial $\mathrm{C} \mathrm{rSO}_{2}$ and $\mathrm{R} \mathrm{rSO}_{2}$ value at minute $(m)$ 0 in the operating room.

These values were transformed into $\mathrm{rSO}_{2}$ variations in regards to initial values according to the following formula $\Delta \mathrm{rSO}_{2}=\left(\left(\mathrm{rSO}_{2}\right.\right.$ measured $-\mathrm{rSO}_{2}$ initial $) / \mathrm{rSO}_{2}$ initial $) \times 100(\%)$. According to literature, a $20 \%$ or more decrease, compared to initial $\mathrm{rSO}_{2}$ values, is considered pathological (negative predictive value $=97 \%$ ). NIRS standard absolute values are not referenced, due to inter and intra-individual variations, except for an inferior threshold common to all regions: a value of $\mathrm{rSO}_{2}<50 \%$ is considered pathological $(8,9,12,13,17)$.

All above mentioned values were recorded along with hemodynamics and respiratory parameters at the same time. On a

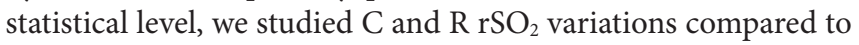
their initial values $\left(\Delta \mathrm{rSO}_{2}\right)$. At the end of the $24 \mathrm{~h}$ post-surgery, we also collected the mean $\mathrm{C}$ and $\mathrm{R} \Delta \mathrm{rSO}_{2}$, recorded by the device.

\section{Fluid Management}

Fluid management and transfusions were decided prescribed at the anesthesiologist's and neonatologist discretion during surgery and after surgery. Collected data regarding FM and transfusion were: number, type, volume (milliliters/kilogram), duration (minutes), initial $\Delta \mathrm{rSO}_{2} \mathrm{C}$ before and after bolus infusion (\%), initial $\Delta \mathrm{rSO}_{2} \mathrm{R}$ before and after bolus infusion (\%).

\section{Epidemiologic and Complications Data Collection}

We collected epidemiologic and complications data for each patient: term birth (in weeks of amenorrhea), gender, birth weight (BW), APGAR at 1/5/10 min, main diagnosis, associated malformations, age at the time of surgery (in days), number of surgeries, duration of the surgery ( $\mathrm{min}$ ), resuming of urine output $<6 \mathrm{~h}$ post-surgery, complications in the first $24 \mathrm{~h}$ post-surgery, duration of NICU stay (in days), total hospitalization duration (in days), and neonatal death or not.

\section{Statistical Analysis}

Statistical analyses were performed using SAS 9.4 software. Qualitative variables were described as sample and percentages and quantitative variables as means and SD or median and Interquartile Range (IQR).

Comparative analysis to compare the average cerebral and renal $\Delta \mathrm{rSO}_{2}$, pre and post FM were performed with a Student $t$-test for paired samples.

Comparative analyses to compare $\mathrm{H} 0-\mathrm{H} 1$ with $\mathrm{H} 1-\mathrm{H} 2$ period during surgery and $\mathrm{H} 0-\mathrm{H} 6$ with $\mathrm{H} 6-\mathrm{H} 24$ period after surgery for the cerebral and renal pathological $\mathrm{rSO}_{2}$ were performed with a Chi-square test.

A generalized estimation equation model with a correlation matrix for structured residues was used first to analyze independently the correlation between: (1) $\mathrm{C}$ and $\mathrm{R} \mathrm{rSO}_{2}$ during the first day (from $\mathrm{m} 0$ of surgery to $\mathrm{H} 24$ after surgery), (2) $\mathrm{C} \mathrm{rSO}_{2}$ with $\mathrm{R}$ rSO, (3) $\mathrm{C}$ and $\mathrm{RrSO}_{2}$ with MAP, (4) $\mathrm{C}$ and $\mathrm{R} \mathrm{rSO}_{2}$ and pre-ductal

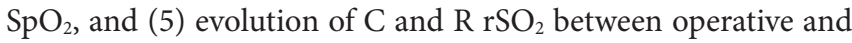
postoperative period. Then, we analyzed the correlation between NIRS values, MAP and pre-ductal $\mathrm{SpO}_{2}$ with time over the surgery and the $24 \mathrm{~h}$ after surgery. Results were expressed in variation ( $95 \%$ confidence interval). $p$-Value $<0.05$ was considered statistically significant. Graphs were performed with Excel in "box plot" style with the following parameters: mean, median, minimum, maximum, quartile 25 , quartile 75 , decile 1 , and decile 9 .

\section{RESULTS}

\section{Population}

Near infrared spectroscopy monitoring was performed on twenty-one patients. Two patients were excluded: reasons were death before surgery $(n=1)$ and no available perioperative data $(n=1)$. Among the 19 patients included, three patients with abdominal wall defect (two gastroschisis and one omphalocele) benefited from a silo pouch stoma allowing the progressive reintegration of the herniated viscera, as it was not feasible to perform the reintegration in one surgical step (complete closure occurred, respectively, 6,8 , and 11 days after the initial surgery). There were thirteen boys (68\%) and six girls (32\%). Population characteristics are listed in Table 1.

After the initial surgery, 16 patients urinated before H6 (84\%). No death or postoperative complications were reported in this patients' cohort. 
TABLE 1 | Population characteristics.

\begin{tabular}{|c|c|c|c|c|c|c|c|c|c|}
\hline Case & Pathologies & $\begin{array}{l}\text { Term birth } \\
\text { (WA + days) }\end{array}$ & $\begin{array}{l}\text { APGAR } \\
\text { 1/5/10 min }\end{array}$ & Gender & $\begin{array}{l}\text { Birth } \\
\text { weight (g) }\end{array}$ & $\begin{array}{l}\text { Age at surgery } \\
\text { (days) }\end{array}$ & $\begin{array}{l}\text { Duration of } \\
\text { surgery (min) }\end{array}$ & $\begin{array}{l}\text { Length of stay in the } \\
\text { neonatal intensive care } \\
\text { unit (days) }\end{array}$ & $\begin{array}{l}\text { Total stay } \\
\text { duration } \\
\text { (days) }\end{array}$ \\
\hline 1 & $\begin{array}{l}\text { Congenital diaphragmatic hernia } \\
(\mathrm{CDH})\end{array}$ & $40+5$ & $2 / x / x$ & $\mathrm{~F}$ & 2,414 & 8 & 120 & 32 & 37 \\
\hline 2 & Gastroschisis & $36+3$ & $9 / 10 / 10$ & M & 3,235 & $0(6)$ & $100(15)$ & 17 & 49 \\
\hline 3 & $\mathrm{CDH}$ & 40 & $8 / 9 / 10$ & M & 4,714 & 3 & 180 & 25 & 27 \\
\hline 4 & $\mathrm{CDH}$ & 39 & 9/9/9 & M & 3,190 & 7 & 90 & 27 & 30 \\
\hline 5 & Omphalocele & 38 & 9/10/10 & M & 3,720 & 0 & 50 & 15 & 21 \\
\hline 6 & Omphalocele & $40+4$ & $10 / 10 / 10$ & $\mathrm{~F}$ & 3,280 & 1 & 20 & 3 & 8 \\
\hline 7 & Necrotizing enterocolitis (NEC) & $38+1$ & $9 / 10 / 10$ & M & 3,100 & 3 & 30 & 21 & 28 \\
\hline 8 & Omphalocele & $30+6$ & $3 / 8 / 9$ & $\mathrm{~F}$ & 1,290 & 1 (9) & $110(45)$ & 27 & 47 \\
\hline 9 & Occlusion & 35 & $8 / 9 / 10$ & M & 3,370 & 3 & 90 & 7 & 37 \\
\hline 10 & Gastroschisis & $36+3$ & $8 / 9 / 10$ & M & 2,855 & 0 & 40 & 21 & 57 \\
\hline 11 & $A E$ & 40 & $1 / 5 / 6$ & M & 2,900 & 0 & 230 & 43 & 84 \\
\hline 12 & NEC & $25+3$ & $6 / 8 / 8$ & M & 927 & 38 & 105 & 116 & 246 \\
\hline 13 & Abdominal tumor & $38+3$ & 9/9/10 & M & 3,540 & 7 & 135 & 9 & 21 \\
\hline 14 & NEC & $29+6$ & $3 / 8 / 10$ & M & 1,640 & 3 & 75 & 75 & 110 \\
\hline 15 & $\mathrm{AE}$ & 41 & $9 / 10 / 10$ & $\mathrm{~F}$ & 2,580 & 0 & 130 & 8 & 15 \\
\hline 16 & Occlusion & 28 & $9 / 8 / 10$ & M & 1,275 & 59 & 60 & 60 & 93 \\
\hline 17 & Gastroschisis & 37 & $8 / 9 / 10$ & $\mathrm{~F}$ & 2,945 & 0 & 20 & 11 & 36 \\
\hline 18 & $\mathrm{CDH}$ & $40+2$ & $1 / 6 / 7$ & $M$ & 3,150 & 2 & 165 & 27 & 43 \\
\hline 19 & Gastroschisis & $32+6$ & $9 / 10 / 10$ & $\mathrm{~F}$ & 2,500 & $0(11)$ & $20(45)$ & 44 & $x$ \\
\hline Mean \pm SD & & $36 \pm 4.7$ & $7 \pm 3 / 9 \pm 1 / 9 \pm 1$ & & $2,770 \pm 941$ & $7 \pm 15(9 \pm 2.5)$ & $93 \pm 59(35 \pm 17)$ & $31 \pm 28$ & $55 \pm 55$ \\
\hline Median \pm IQR & & $38 \pm 6.1$ & $8 \pm 5 / 9 \pm 1 / 10 \pm 1$ & & $2,945 \pm 801$ & $2 \pm 5(9 \pm 2.5)$ & $90 \pm 80(45 \pm 15)$ & $25 \pm 25$ & $37 \pm 28$ \\
\hline
\end{tabular}

Characteristics from the second surgery are mentioned within brackets.

WA, weeks of amenorrhea; IQR, interquartile range. 


\section{Evolution of the $\mathrm{C}$ and $\mathrm{R} \mathrm{rSO}$} The Total Study Period (Surgery and Post-Surgery)

Mean initial $\mathrm{C}$ and $\mathrm{R} \mathrm{rSO}_{2}$ values were, respectively, 79.11\% \pm 9.92 and $79.37 \% \pm 11.31$ for the first surgery; $81 \% \pm 8.72$ and $72.67 \% \pm 11.02$ for the second surgery ( $n=3$ patients).

Median variations of $\mathrm{C}$ and $\mathrm{R} \mathrm{rSO}_{2}$, at the $24 \mathrm{~h}$, were $-0.6 \% \pm 9.1$ (IQR) and $-5.55 \% \pm 15.25$ (IQR) for the first surgery; $-4.47 \% \pm 16.29$ and $-10.43 \% \pm 4.96$ for the second one. Median variations of $\mathrm{C}$ and $\mathrm{R} \mathrm{rSO}_{2}$, at $24 \mathrm{~h}$, according to the pathology are reported in Table 2 .

$\mathrm{C}$ and $\mathrm{R} \mathrm{rSO}_{2}$ values, as well as hemodynamics and respiratory parameters are reported in Figures $\mathbf{1}$ and $\mathbf{2}$.

We observed a total of 90 pathological values in 12 patients; $63 \%(n=57) \mathrm{R} \mathrm{rSO}_{2}$ and $37 \%(n=33) \mathrm{C} \mathrm{rSO}_{2} ; 44 \%(n=40)$ were reported during surgery and $55 \%(n=50)$ post-surgery. The distribution of pathological values according to time is reported in Table 3 and the distribution of pathological values according to the pathology in Table 4. The pathological values and corresponding MAP, HR, and pre-ductal $\mathrm{SpO}_{2}$ (\%) values, in regards to acute event are described in Table 5.

\section{Acute Events during Pathological $\mathrm{rSO}_{2}$}

We analyzed events related to $\mathrm{rSO}_{2}$ pathological values. We noted that it matched with events carrying risks in the intraoperative or postoperative period (Table 5). During the intraoperative period, these events were mainly incision, bowel manipulation, viscera reduction, tracheoesophageal fistula occlusion, and abdominal wall closure. Other acute events were related to respiratory events (tracheal or nasotracheal tube obstruction and accidental ventilation arrest), progressive viscera reintegration, pain [evaluated via the newborn baby scaled named EDIN (18); scale as $>5$ ]. We observed emesis during pathological $\mathrm{rSO}_{2}$ events in the postoperative period. But in some cases $(n=8)$, no cause was identified. Interestingly, hemodynamics parameters (MAP, HR, and pre-ductal $\mathrm{SpO}_{2}$ ) did not show pathological variations.

\section{Surgery}

During surgery, $\mathrm{C} \mathrm{rSO}_{2}$ values were stable, pathological values occurring only punctually and briefly; while average ${\mathrm{R} \mathrm{rSO}_{2}}_{2}$ values tended to decrease gradually (Figure 1; Table 3) for the same period, without statistical significance (Table 3) There was no significant difference between $\mathrm{m} 0-\mathrm{m} 30$ and $\mathrm{m} 30-\mathrm{m} 120$ period during surgery for pathological $\mathrm{C} \mathrm{rSO}_{2}$ occurrence

TABLE 2 | Average variation of $\mathrm{CrSO}_{2}$ and $\mathrm{R} \mathrm{rSO}_{2}$ according to the pathology.

\begin{tabular}{lcc}
\hline & $\begin{array}{c}\text { Average } \Delta \mathbf{r S O}_{\mathbf{2}} \mathbf{C} \\
\text { (median } \pm \text { IQR) }\end{array}$ & $\begin{array}{c}\text { Average } \mathbf{\Delta r S O _ { 2 } \mathbf { R }} \\
\text { (median } \pm \text { IQR) }\end{array}$ \\
\hline Congenital diaphragmatic & $-2.65 \pm 4.63$ & $-13.15 \pm 7.45$ \\
hernia $(n=4)$ & $7.10 \pm 9.8$ & $-6.90 \pm 21.10$ \\
Gastroschisis $(n=4)$ & $0.05 \pm 8.05$ & $-8.35 \pm 5.08$ \\
Omphalocele $(n=3)$ & $-0.30 \pm 4$ & $4.45 \pm 1.85$ \\
Esophageal atresia $(n=2)$ & $1.20 \pm 10.80$ & $-11.50 \pm 12.20$ \\
Necrotizing enterocolitis $(n=3)$ & $-9.45 \pm 4.55$ & $-4.85 \pm 4.85$ \\
Occlusion $(n=2)$ & 4.20 & -2.70 \\
Tumor $(n=1)$ & & \\
\hline
\end{tabular}

$I Q R$, interquartile range.
(Chi-square $=2.669 ; p=0.102)$ and ${\mathrm{R} \mathrm{rSO}_{2}}_{2}$ (Chi-square $=1.939$; $p=0.164)$. During the postoperative period, the lower mean values for $\mathrm{C}$ and $\mathrm{R} \mathrm{rSO}_{2}$ were evidenced in the first $6 \mathrm{~h}$ post-surgery, gradually reversing to normal values over time. Regardless, the difference in $\mathrm{C}$ and $\mathrm{R} \mathrm{rSO}_{2}$ parameters between $\mathrm{H} 0-\mathrm{H} 6$ post-surgery and those between $\mathrm{H} 6-\mathrm{H} 24$ was not statistically significant $\left(\mathrm{C} \mathrm{rSO}_{2}\right.$ Chi-square $=1.237 ; p=0.266$ and $\mathrm{R} \mathrm{rSO}_{2}$ Chi-square $=1.391 ; p=0.238$ ).

During surgery, two patients presented both pathological $\mathrm{C}$ and $\mathrm{R} \mathrm{rS0} 2$ values: a patient with $\mathrm{NEC}\left(1 \mathrm{C} \mathrm{rSO}_{2}\right.$ and $2 \mathrm{R} \mathrm{sSO}_{2}$ pathological values) and a patient with bowel obstruction (2 $\mathrm{C}$ $\mathrm{rSO}_{2}$ and $2 \mathrm{R} \mathrm{sSO}_{2}$ pathological values). Two patients presented

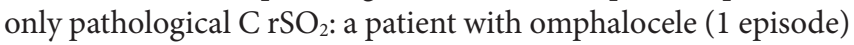
and a patient with EA (2 episodes). Seven patients presented isolated pathological $\mathrm{R}$ rS02: three patients with $\mathrm{CDH}$ (respectively, 9, 7, and 6 episodes); a patient with gastroschisis during the primary surgery for herniated viscera reintegration (with delayed final closure and silo pouch stoma; 1 episode); another patient with gastroschisis (1 episode); a patient with EA (5 episodes); and a patient with bowel obstruction (1 episode).

Hemodynamics and respiratory parameters were stable during the surgery (Figure 1).

\section{The Post-Surgical Period}

During the first $6 \mathrm{~h}$ after surgery, we observed a decrease of $\mathrm{C} \mathrm{rSO}_{2}$ and a slight reduction in renal values. Moreover, most pathological values, $60 \%(n=30 / 50)$, were observed during this period, afterward $\mathrm{rSO}_{2}$ tended to return progressively to its initial values.

During the post-surgical period, four patients presented both pathological $\mathrm{C}$ and $\mathrm{R} \mathrm{rSO}_{2}$ : two patients with $\mathrm{CDH}$ (respectively, one cerebral and one renal episode; seven cerebral episodes and two renal episodes); and two patients with bowel obstructions (respectively, two cerebral episodes and three renal episodes; three cerebral episodes, and one renal episode). Three patients presented isolated pathological $\mathrm{C} \mathrm{rSO}_{2}$ episodes: a patient with NEC (1 episode), a patient with gastroschisis after the secondary abdominal closure (11 episodes, including 5 episodes of pathological values in the first $6 \mathrm{~h}$ post-surgery), and another patient with gastroschisis (3 episodes).

Seven patients presented isolated pathological $\mathrm{R} \mathrm{rSO}_{2}$ episodes: a patient with $\mathrm{CDH}$ (one episode), two patients with omphalocele (three episodes each), a patient with NEC (two episodes); a patient with abdominal tumor (two episodes) and two patients with gastroschisis with delayed abdominal closure (respectively, two episodes and one episode). Decreasing NIRS values were noted after the two procedures in the first case, but only after the initial procedure in the second case.

Hemodynamics (MAP and HR) and respiratory (pre- and post-ductal $\mathrm{SpO}_{2}$ ) parameters were stable and normal (Figure 2).

\section{$\mathrm{C}$ and $\mathrm{R} \mathrm{rSO}_{2}$ Correlation}

The analysis of the $\mathrm{C} \mathrm{rSO}_{2}$ correlation with hemodynamics parameters (MAP, $\mathrm{SpO}_{2}$, intraoperative or postoperative period, $\mathrm{m} 0-\mathrm{H} 24$ time period) was significant for the $\mathrm{m} 0-\mathrm{H} 24$

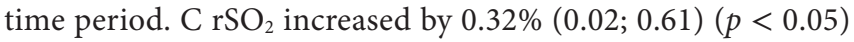
per hour between $\mathrm{m} 0$ and $\mathrm{H} 24$, independently from all other 

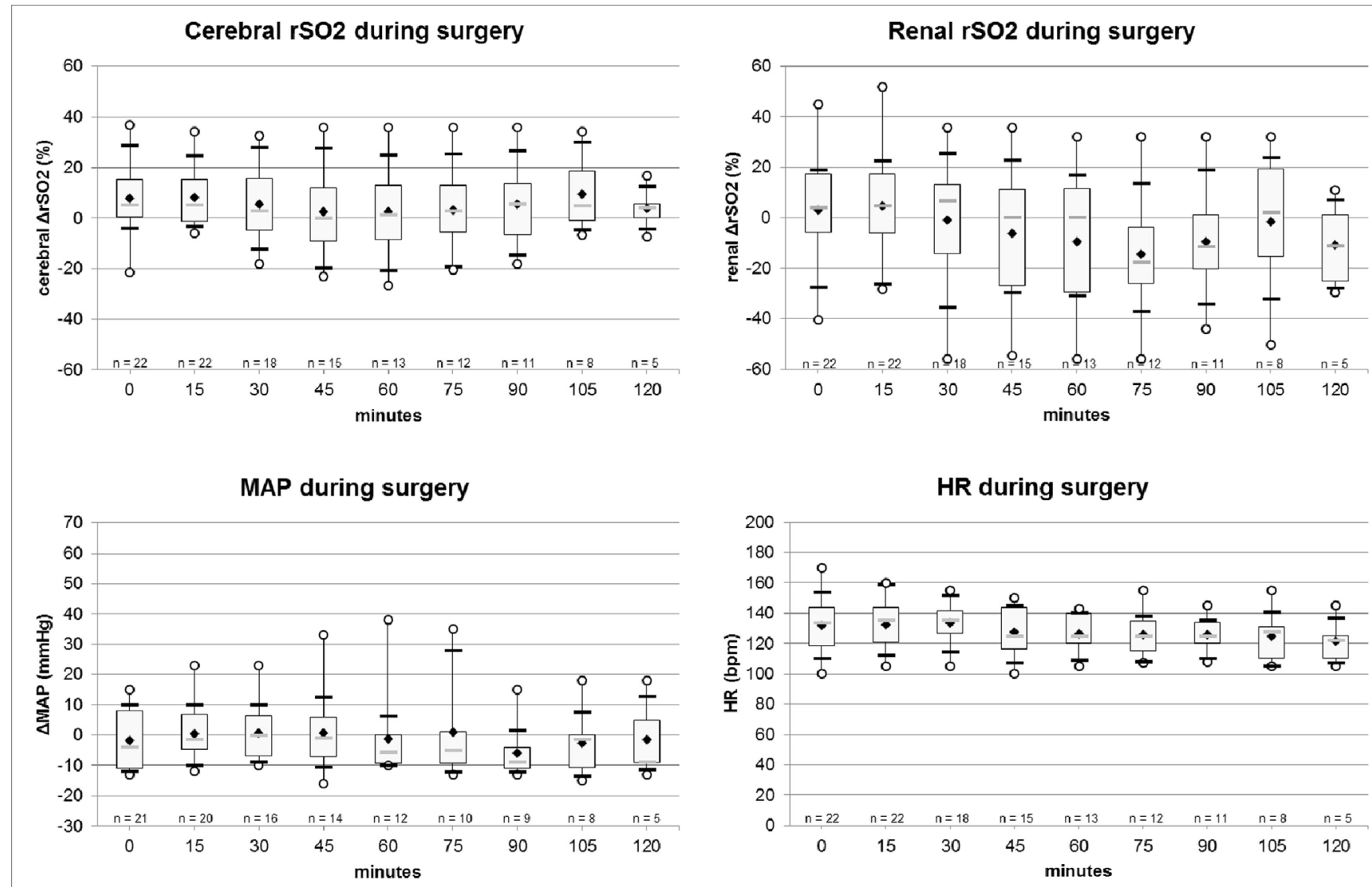

Pre ductal SpO2 during surgery
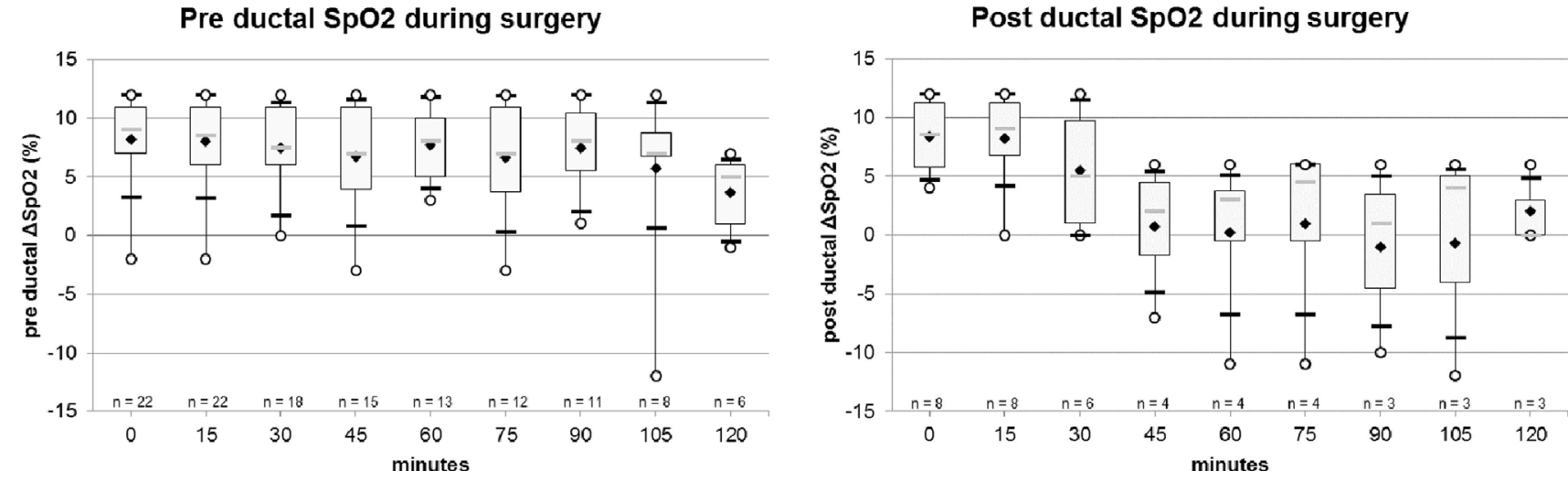

FIGURE 1 | Evolution of cerebral and renal $\mathrm{rSO}_{2}(\%)$, mean arterial pressure (MAP) (mmHg), heart rate (HR) (bpm), pre and post-ductal SpO ${ }_{2}$ values, during surgery. Legend: $\mathrm{O}$, minimum and maximum; - , first and ninth decile; gray - , median; white

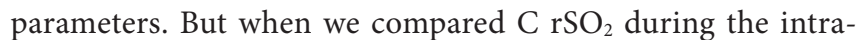
operative period versus the postoperative period, we noted a

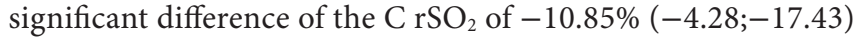
$(p<0.01)$. $\mathrm{C} \mathrm{rSO}_{2}$ were significantly higher during intraoperative period than postoperative period. A progressive return to normal of the values is observed after the 6th hour. No correla-

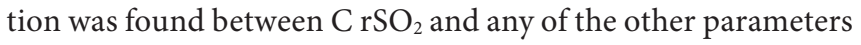
studied.

The analysis of the correlation of $\mathrm{R} \mathrm{rSO}_{2}$ with the same parameters (MAP, $\mathrm{SpO}_{2}$, intraoperative or postoperative period, $\mathrm{m} 0-\mathrm{H} 24$ time period) was also significant for the $\mathrm{m} 0-\mathrm{H} 24$ time period. $\mathrm{R} \mathrm{rSO}_{2}$ increased by $0.71 \%(0.06 ; 1.36)(p<0.05)$ per hour between $\mathrm{m} 0$ and $\mathrm{H} 24$. There was also a significant association between $\mathrm{R} \mathrm{rSO}_{2}$ and pre-ductal $\mathrm{SpO}_{2}$. Renal $\mathrm{rSO}_{2}$ values increased by $1.50 \%(0.46 ; 2.53)(p<0.01)$ when pre-ductal $\mathrm{SpO}_{2}$ values increased by $1 \%$, independently from other parameters studied. No correlation with the other parameters studied was unveiled.

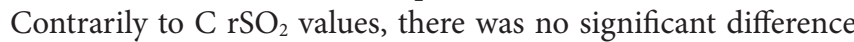
noted for $\mathrm{R} \mathrm{rSO}_{2}$ values between the intraoperative period and postoperative period. 

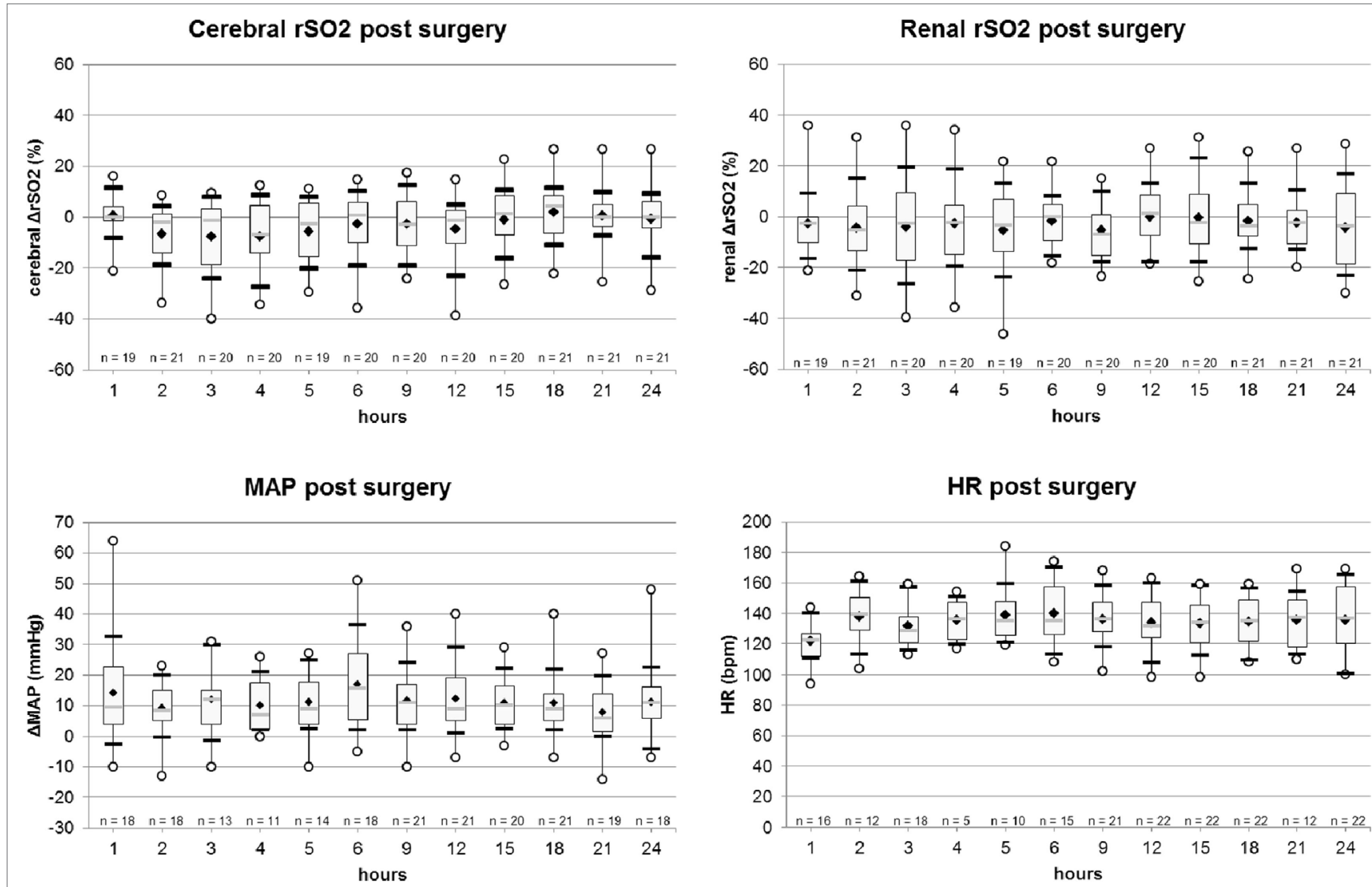

Pre ductal SpO2 post surgery

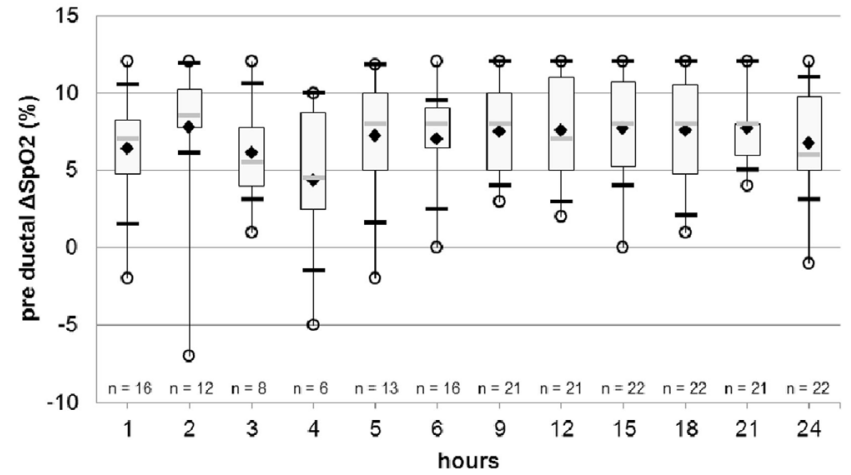

Post ductal SpO2 post surgery

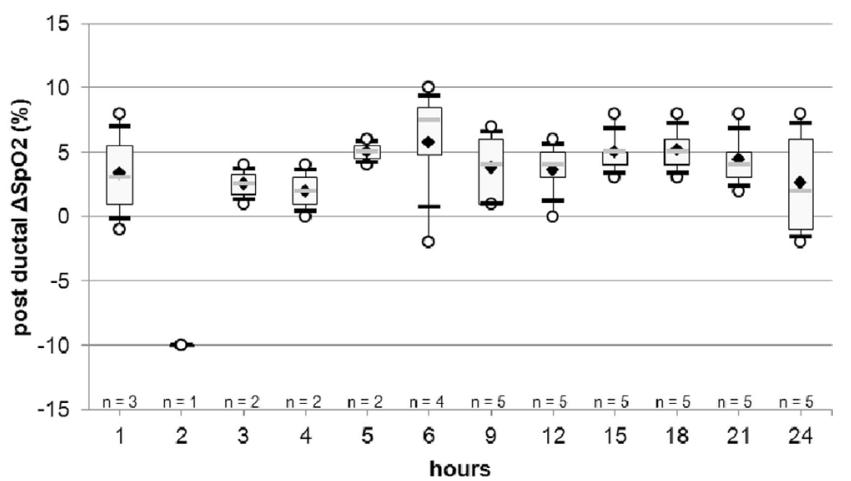

FIGURE 2 | Evolution of cerebral and renal $\mathrm{rSO}_{2}(\%)$, mean arterial pressure (MAP) (mmHg), heart rate (HR) (bpm), pre and post ductal SpO ${ }_{2}$ values, from $\mathrm{H} 1$ to $\mathrm{H} 6$

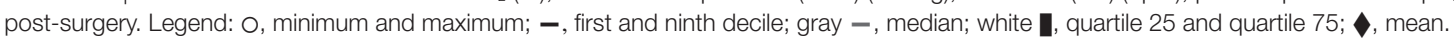

The $\mathrm{C} \mathrm{rSO}_{2}$ with $\mathrm{R} \mathrm{rSO}_{2}$ correlation analysis during the study (during and after surgery) was significant, we noted that ${\mathrm{C} \mathrm{rSO}_{2}}_{2}$ increased by $0.22 \%(0.04 ; 0.39)(p<0.05)$ when $\mathrm{R} \mathrm{rSO}_{2}$ increased by $1 \%$.

\section{Fluid Management}

There were 55 FM procedures in total, 34 (62\%) with albumin, 16 (29\%) with crystalloids, and 5 (9\%) with transfusion (4 red cell concentrates and 1 platelet transfusion). The volume of the FM was on average $10.5 \pm 4.5 \mathrm{ml} / \mathrm{kg}$ and was administered in $47 \pm 22 \mathrm{~min}$.
No $\mathrm{rSO}_{2}$ data were available for nine FM. There were seven cases of pathological $\mathrm{rSO}_{2}, 1 \mathrm{C}$ and $6 \mathrm{R}$ episodes before FM. We observed that $71 \%$ of these pathological $\mathrm{rSO}_{2}(5 / 7)$ were improved by FM: one patient with gastroschisis and one patient with omphalocele (with delayed final closure and silo pouch stoma), one $\mathrm{CDH}$, one patient with bowel obstruction, and one patient abdominal tumor.

Among the non-pathological $\mathrm{rSO}_{2}$ patients, we noticed that only one had improved by $20 \%$ (patient with gastroschisis at the beginning of surgery, just after the transfer from NICU to operative room). The comparison of mean $\mathrm{C}$ and $\mathrm{R} \Delta \mathrm{rSO}_{2}$ values pre 
and post FM were, respectively, $-0.39 \pm 7.77(p=0.736)$ and $0.77 \pm 18.99(p=0.786)$.

\section{DISCUSSION}

Near infrared spectroscopy monitoring was studied in multiple surgical and medical fields, for pediatric and adult patients alike (12-14, 19-22).

TABLE 3 | Cerebral and renal pathological $\mathrm{rSO}_{2}$ values during or after surgery.

\begin{tabular}{cccc}
\hline & Cerebral & Renal & Total \\
\cline { 2 - 4 } & $\begin{array}{c}\text { Frequency } \\
\mathbf{( \% )}\end{array}$ & $\begin{array}{c}\text { Frequency } \\
\mathbf{( \% )}\end{array}$ & $\begin{array}{c}\text { Frequency }(\boldsymbol{n}=\mathbf{9 0}) \\
\mathbf{( \% )}\end{array}$ \\
\hline During surgery & $6(6.7)$ & $34(37.8)$ & $40(44.5)$ \\
0-30 min & $1(1.1)$ & $10(11.1)$ & $11(12.2)$ \\
30-60 min & $4(4.5)$ & $11(12.2)$ & $15(16.7)$ \\
60-90 min & $1(1.1)$ & $8(8.9)$ & $9(10)$ \\
90-120 min & 0 & $4(4.5)$ & $4(4.5)$ \\
$>120$ min & 0 & $1(1.1)$ & $1(1.1)$ \\
After surgery & $27(30)$ & $23(25.5)$ & $50(55.5)$ \\
Before H6 & $16(17.8)$ & $14(15.6)$ & $30(33.3)$ \\
After H6 & $11(12.2)$ & $9(10)$ & $20(22.2)$ \\
Total & $33(36.7)$ & $57(63.3)$ & $90(100)$ \\
\hline
\end{tabular}

TABLE 4 | Cerebral and renal pathological $\mathrm{rSO}_{2}$ values during or after surgery according to the pathology.

\begin{tabular}{|c|c|c|c|c|c|}
\hline & \multicolumn{2}{|c|}{ During surgery } & \multicolumn{2}{|c|}{ After surgery } & \multirow{2}{*}{$\begin{array}{c}\text { Total } \\
\begin{array}{c}\text { Frequency } \\
(\%)\end{array}\end{array}$} \\
\hline & Cerebral & Renal & Cerebral & Renal & \\
\hline $\begin{array}{l}\text { Congenital } \\
\text { diaphragmatic hernia }\end{array}$ & 0 & 23 & 8 & 4 & $35(39 \%)$ \\
\hline Gastroschisis & 0 & 1 & 14 & 5 & $20(22 \%)$ \\
\hline Omphalocele & 1 & 0 & 0 & 6 & 7 (8\%) \\
\hline Esophageal atresia & 2 & 5 & 0 & 0 & 7 (8\%) \\
\hline $\begin{array}{l}\text { Necrotizing } \\
\text { enterocolitis }\end{array}$ & 1 & 2 & 1 & 2 & $6(7 \%)$ \\
\hline Occlusion & 2 & 3 & 4 & 4 & $13(14 \%)$ \\
\hline Tumor & 0 & 0 & 0 & 2 & $2(2 \%)$ \\
\hline Total (frequency in \%) & $6(7 \%)$ & $34(38 \%)$ & 27 (30\%) & $23(25 \%)$ & $90(100 \%)$ \\
\hline
\end{tabular}

Based on literature data, there are no absolute values of reference for NIRS measures, regardless of the organ of interest because of inter-individual and inter-situation variations. It was previously established that a $20 \%$ decrease of the initial $\mathrm{rSO}_{2}$ is a sign of tissue hypoperfusion, and an absolute value of cerebral $\mathrm{rSO}_{2}<50 \%$ underlines a strong risk of brain damage visible on imaging data with a potential risk of disability, and an absolute $\mathrm{rSO}_{2}$ value (cerebral or somatic) $<30 \%$ is considered a vital emergency with severe visceral ischemia in progress $(8,9,17)$.

Regarding neonatal digestive surgery, Conforti et al. (15) studied a series of $\mathrm{CDH}$ and showed that reintegration of viscera in the abdominal cavity was associated to decreased renal NIRS values. However, Westgarth-Taylor et al. used NIRS similarly to evaluate the impact of viscera reintegration on renal values. They aimed to determine if in case of $\mathrm{CDH}$, oliguria was due to intraabdominal hypertension by analyzing renal $\mathrm{rSO}_{2}$ during surgery. They documented that iaP increase and $\mathrm{rSO}_{2}$ decrease did not correlate with oliguria, which was certainly related to various factors such as frailty, FM issues, difficulty in measuring loss of fluid in a precise manner.

We observed an intraoperative reduction of renal $\mathrm{rSO}_{2}$ during or after herniated viscera reintegration; however, cerebral $\mathrm{rSO}_{2}$ values were stable in our cases, possibly explained by high $\mathrm{FiO}_{2}$ (>60\%) and high PIP (>20 mmHg) used during the intraoperative time with sustained cerebral self-regulation. These data could possibly reflect the effectiveness of the resuscitation procedure and surgical management regarding the choice of reintegrating the herniated viscera methods (in one or two surgical times). It is well known that intra-abdominal reintegration of abdominal herniated organs induces an increase of iaP that could deteriorate abdominal tissue by compression of the inferior vena cava (15). The need for elevated PIP to fight the increased abdominal pressure in order to promote effective ventilation increases this self-sustained phenomenon.

This is, in our opinion, one of the major reasons for NIRS monitoring in these situations. It is clear that even if the use of NIRS during our study was not scientifically validated, pathological values guided our choices, mainly concerning herniated viscera reintegration in one surgery or two surgeries.

TABLE 5 | Repartition of pathological $r \mathrm{rO}_{2}$ and corresponding mean arterial pressure (MAP) (mmHg), heart rate (HR) (bpm), and pre-ductal $\mathrm{SpO}_{2}$ values, in regard to acute event.

\begin{tabular}{|c|c|c|c|c|c|}
\hline & $n$ & $\Delta \mathrm{rSO}_{2}($ mean $\pm \mathrm{SD})$ & $\Delta \mathrm{MAP}($ mean $\pm \mathrm{SD})$ & $H R($ mean \pm SD) & $\Delta$ Pre-ductal $\mathrm{SpO}_{2}($ mean $\pm \mathrm{SD})$ \\
\hline Incision & 4 & $-30.85 \pm 7.91$ & $-3.75 \pm 12.82$ & $132 \pm 11.22$ & $6.00 \pm 5.89$ \\
\hline Bowel manipulation & 24 & $-34.69 \pm 11.57$ & $4.43 \pm 16.62$ & $134 \pm 13.016$ & $4.33 \pm 4.98$ \\
\hline Viscera reduction & 4 & $-23.15 \pm 2.27$ & $-9.00 \pm 2.83$ & $130 \pm 3.32$ & $9.50 \pm 3.00$ \\
\hline Tracheoesophageal fistula occlusion & 2 & $-23.80 \pm 0.85$ & $-13.00 \pm 4.24$ & $110 \pm 3.54$ & $2.00 \pm 7.07$ \\
\hline Progressive viscera reintegration & 4 & $-24.53 \pm 5.23$ & $-0.25 \pm 8.54$ & $124 \pm 8.23$ & $9.50 \pm 2.08$ \\
\hline Abdominal wall closure & 2 & $-27.10 \pm 10.04$ & $0.50 \pm 10.61$ & $135 \pm 14.14$ & $5.00 \pm 1.41$ \\
\hline Emesis & 3 & $-23.03 \pm 2.67$ & Unknown & $114 \pm 14.01$ & $8 \pm 0.00$ \\
\hline Tracheal or nasotracheal tube obstruction & 17 & $-29.41 \pm 7.49$ & $12.27 \pm 13.47$ & $134 \pm 19.14$ & $5.42 \pm 4.46$ \\
\hline Accidental ventilation arrest & 7 & $-27.20 \pm 4.79$ & $-2 \pm 13.39$ & $145 \pm 1.00$ & $1.75 \pm 2.06$ \\
\hline Pain (EDIN >5) & 15 & $-24.89 \pm 6.18$ & $15.75 \pm 8.76$ & $137 \pm 9.45$ & $8.44 \pm 2.70$ \\
\hline Unknown & 8 & $-26.26 \pm 6.25$ & $11.57 \pm 8.92$ & $144 \pm 15.19$ & $8.25 \pm 3.33$ \\
\hline
\end{tabular}

EDIN, "Echelle de douleur et d'inconfort du nouveau-né" "Pain and discomfort new-born baby scaled." 
During the postoperative period, we observed that NIRS variations were the most frequent. Interestingly, the first $6 \mathrm{~h}$ postsurgery tended to be the most at risk in terms of pathological $\mathrm{rSO}_{2}$ decrease with a risk of systemic organ failure. Constant monitoring during the first $6 \mathrm{~h}$ post-surgery is essential. After this time, fluid balance was restored, and iaP tended to gradually return to normal levels, probably due to a decrease of the inflammation and edema, elimination of postoperative pneumoperitoneum, progressive disappearance of the ileus, and evacuation of the intra-intestinal content, as well as adaptation of the abdominal wall and skin $(2,7)$.

We observed a correlation between cerebral and renal $\mathrm{rSO}_{2}$ values and duration of care management. We also found a significant association between renal $\mathrm{rSO}_{2}$ values and pre-ductal $\mathrm{SpO}_{2}$ : renal $\mathrm{rSO}_{2}$ values were higher when the saturation increased. NIRS being a monitoring tool for tissue oxygenation, these values were expected and only reflect the association between variations in regional saturation and global saturation (8-11).

However, we did not observe a significant association between cerebral $\mathrm{rSO}_{2}$ and pre-ductal $\mathrm{SpO}_{2}$. This absence of correlation could be explained by self-regulation of cerebral oxygenation by adaptation mechanisms to the detriment of peripheral tissue oxygenation. Regional cerebral saturation decreases when these mechanisms go into overload (15). These results promote the hypothesis that measuring both cerebral and renal $\mathrm{rSO}_{2}$ is highly relevant in the hemodynamic monitoring of neonatal digestive surgeries to detect central and peripheral hypoperfusion.

We did not evidence a significant association between renal and cerebral $\mathrm{rSO}_{2}$ and MAP. We could deduce that either $\mathrm{rSO}_{2}$ values were not able to predict blood pressure evolution or more probably $\mathrm{rSO}_{2}$ and $\mathrm{SpO}_{2}$ variations were occurring early on in order to implement a treatment before MAP could decrease.

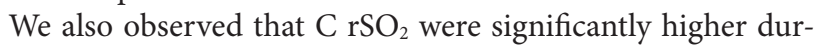
ing the intraoperative period than the postoperative period. The high $\mathrm{FiO}_{2}(>60 \%)$ used during the intraoperative period could be an explanation. These $\mathrm{High} \mathrm{FiO}_{2}$ values could have had a major impact on the recordings in the operating room.

One other clinically relevant finding of this study was the response of NIRS to FM when $\mathrm{rSO}_{2}$ decreased by $20 \%$ or more. FM with adequate volumes was beneficial, particularly in case of major fluid losses frequently observed in progressive reintegration of the herniated viscera. This was also observed for red cell transfusions, probably because the increased in hemoglobin values led to a better oxygenation, and thus improved $\mathrm{rSO}_{2}$. These data are concordant with the literature $(9,13,15)$. NIRS seems to answer independently from all other parameters used during FM (MAP, $\mathrm{HR}, \mathrm{SpO}_{2}$ ) when measured. We believe that NIRS variations could be detected earlier than usual monitoring parameters. So NIRS anticipated changes in another parameter.

Our study had some limitations. First, the population was heterogeneous according to gestational age and BW. NIRS values in premature neonates might be different from full-term neonates, $\mathrm{rSO}_{2}$ values can be over or underestimated since the NIRS analytic field can vary in light of thinner skin and bone mass for identical NIRS wavelength trajectories, yet this phenomenon can be compensated by analyzing $\mathrm{rSO}_{2}$ variations. There could be some differences because of bilirubin levels that are often higher in premature neonates. Cerebral self-regulation differs according to birth term and postnatal age, which could impact $\mathrm{rSO}_{2}$ values. Second, these different pathologies are not common explaining the small sample of subjects. At last, obtaining exhaustive data was quite delicate due to recording methods (dedicated monitoring sheets). These limitations required us to carefully interpret our results, especially for FM.

However, to our knowledge, this is the first study reporting data showing the evolution of cerebral and renal regional oxygen transport during and after neonatal digestive surgeries. This type of surgery bears a major risk of homeostatic imbalance that could be life threatening to these peculiarly vulnerable patients. Using the most precise and reliable measurement of visceral oxygenation and regional microcirculation is highly relevant in these situations.

\section{CONCLUSION}

Near infrared spectroscopy provides helpful information to guide the surgery (bowel manipulation, viscera reduction) and may represent an early warning for identifying patients requiring resuscitation. Monitoring during surgery and in the first $6 \mathrm{~h}$ postsurgery is essential, this period bearing the most risk of systemic organ failure.

\section{ETHICS STATEMENT}

This study was carried out in accordance with the recommendations of the "Institutional Review Board of the CHU of Reims." Our patients were too young (neonates) to give their consent. Their parents were informed of this study and the procedure and could refuse the study. Each parent of the children of this study had a standard written informed consent about the care and the use of all data concerning their child hospitalized in our university hospital, as for over patients hospitalized in our unit in our university hospital. According to our institutional review board that approved our study protocol, no specific written consent was required, just the standard written consent of our university hospital. Actually NIRS recording is considered a usual medical care, as many NICUs and operative room use it routinely in neonates. Moreover, this study was purely observational, without any decision taken or treatment introduced regarding to the NIRS information.

\section{AUTHOR CONTRIBUTIONS}

JB: conceptualized and designed the study, coordinated, supervised, and participated in the acquisition of data, drafted the initial manuscript, and approved the final manuscript as submitted. GL and M-LP-M: participated in the acquisition and interpretation of data, reviewed and revised the manuscript critically for important intellectual content, and approved the final manuscript as submitted. CM: carried out the initial statistical analyses, reviewed and revised the manuscript critically for important intellectual content, and approved the final manuscript as submitted. EG and CG: reviewed the conceptualization 
and the design of the study, participated in the acquisition and interpretation of data, reviewed and revised the manuscript critically for important intellectual content, and approved the final manuscript as submitted. NB and CF: participated to acquisition of data, reviewed and revised the manuscript critically for important intellectual content, and approved the final manuscript as submitted. All of the authors approved the final manuscript as submitted and agree to be accountable for all aspects of the work in ensuring that questions related to the accuracy or integrity of any part of the work are appropriately investigated and resolved.

\section{REFERENCES}

1. Lejus C, Biard M, Leclair M-D. Urgences chirurgicales néonatales [Neonatal surgical emergencies]. EMC - Anesth Réanim (2011) 8(2):1-16. doi:10.1016/ S0246-0289(11)44734-4

2. Gamba P, Midrio P. Abdominal wall defects: prenatal diagnosis, newborn management, and long-term outcomes. Semin Pediatr Surg (2014) 23(5): 283-90. doi:10.1053/j.sempedsurg.2014.09.009

3. Badillo A, Gingalewski C. Congenital diaphragmatic hernia: treatment and outcomes. Semin Perinatol (2014) 38(2):92-6. doi:10.1053/j. semperi.2013.11.005

4. Beacco C, Panczer M. Monitorage du débit cardiaque et de l'hémodynamique [Cardiac output and hemodynamic monitoring]. IRBM News (2012) 33(5):100-15. doi:10.1016/j.irbmnw.2012.09.003

5. Cannesson M, Desebbe O, Piriou V, Lehot J-J. Monitorage continu et automatisé de la précharge dépendance en anesthésie et en réanimation: intérêts et limites [Automatic and continuous monitoring of preload dependence in the perioperative period: interests and limits]. Ann Fr Anesth Réanim (2010) 29(6):452-63. doi:10.1016/j.annfar.2010.03.010

6. Kirkpatrick AW, Roberts DJ, De Waele J, Jaeschke R, Malbrain M, De Keulenaer B, et al. Intra-abdominal hypertension and the abdominal compartment syndrome: updated consensus definitions and clinical practice guidelines from the World Society of the Abdominal Compartment Syndrome. Intensive Care Med (2013) 39:1190-206. doi:10.1007// s00134-013-2906-z

7. Newcombe J, Mathur M, Ejike JC. Abdominal compartment syndrome in children. Crit Care Nurse (2012) 32(6):51-61. doi:10.4037/ccn2012761

8. Steppan J, Hogue CW Jr. Cerebral and tissue oximetry. Best Pract Res Clin Anaesthesiol (2014) 28(4):429-39. doi:10.1016/j.bpa.2014.09.002

9. Raux O, Sola C, Macq C, Dadure C. Loxymétrie cérébrale transcutanée en anesthésie Pédiatrique [Cerebral near-infrared spectroscopy (NIRS) in paediatric anaesthesia]. Ann Fr Anesth Réanim (2013) 32(1):e49-53. doi:10.1016/j. annfar.2012.10.025

10. Francony G, Bouzat P, Payen J-F. Monitorage par spectroscopie de proche infrarouge en neuroréanimation [Near infrared spectroscopy monitoring in the neurointensive care]. Ann Fr Anesth Réanim (2012) 31(6):e133-6. doi:10.1016/j.annfar.2012.04.017

11. Panczer M. L'oxymétrie tissulaire ou near infrared spectroscopy (NIRS) [Tissue oxymetry or near infrared spectroscopy (NIRS)]. IRBM News (2011) 32(4-5):103-10. doi:10.1016/j.irbmnw.2011.08.006

12. Hirsch JC, Charpie JR, Gurney JG, Ohye RG. Role of near infrared spectroscopy in pediatric cardiac surgery. Prog Pediatr Cardiol (2010) 29(2):93-6. doi:10.1016/j.ppedcard.2010.06.003

13. Sood BG, McLaughlin K, Cortez J. Near-infrared spectroscopy: applications in neonates. Semin Fetal Neonatal Med (2015) 20(3):164-72. doi:10.1016/j. siny.2015.03.008

\section{ACKNOWLEDGMENTS}

Thank you to Ms. Bénédicte Clement for her advice and her English review of the manuscript. A conference paper was accepted by The European Society of Pediatric and Neonatal Intensive Care (ESPNIC) meeting, in June 6-9, 2017.

\section{FUNDING}

The research was conducted in the absence of funding sources.

14. Conforti A, Giliberti P, Mondi V, Valfré L, Sgro S, Picardo S, et al. Near infrared spectroscopy: experience on esophageal atresia infants. J Pediatr Surg (2014) 49(7):1064-8. doi:10.1016/j.jpedsurg.2014.01.010

15. Conforti A, Giliberti P, Landolfo F, Valfrè L, Columbo C, Mondi V, et al Effects of ventilation modalities on near-infrared spectroscopy in surgically corrected CDH infants. J Pediatr Surg (2016) 51(3):349-53. doi:10.1016/j. jpedsurg.2015.07.021

16. Westgarth-Taylor C, de Lijster L, van Bogerijen G, Millar AJW, Karpelowsky J. A prospective assessment of renal oxygenation in children undergoing laparoscopy using near-infrared spectroscopy. Surg Endosc (2013) 27(10):3696-704. doi:10.1007/s00464-013-2950-3

17. Moerman A, Wouters P. Near-infrared spectroscopy (NIRS) monitoring in contemporary anesthesia and critical care. Acta Anaesthesiol Belg (2010) 61(4):185-94.

18. Bordin C, Leclaire M, Demeester A. L'échelle de douleur et d'inconfort du nouveau-né (EDIN). Etude de validité portant sur 160 nouveau-nés en maternité entre quatre et 12 heures de vie [Pain and dyscomfort new-born baby scaled (EDIN). Validity study on 160 new-born in a maternity between four and 12 hours of life]. RevSage Femme (2012) 11(3):120-7.doi:10.1016/j.sagf.2012.05.005

19. Siegenthaler N, Giraud R, Piriou V, Romand J-A, Bendjelid K. Altérations de la microcirculation dans les états de choc: physiopathologie, surveillance et traitement [Microcirculatory alterations in critically ill patients: pathophysiology, monitoring and treatments]. Ann Fr Anesth Réanim (2010) 29(2):135-44. doi:10.1016/j.annfar.2009.10.023

20. Wallois F, Patil A, Héberlé C, Grebe R. EEG-NIRS in epilepsy in children and neonates. Neurophysiol Clin (2010) 40(5-6):281-92. doi:10.1016/j. neucli.2010.08.004

21. Wallois F, Mahmoudzadeh M, Patil A, Grebe R. Usefulness of simultaneous EEG-NIRS recording in language studies. Brain Lang (2012) 121(2):110-23. doi:10.1016/j.bandl.2011.03.010

22. Örmeci T, Alkan-Bozkaya T, Özyüksel A, Ersoy C, Ündar A, Akçevin A, et al. Correlation between cerebral-renal near-infrared spectroscopy and ipsilateral renal perfusion parameters as clinical outcome predictors after open heart surgery in neonates and infants: cerebral-renal NIRS and ipsilateral renal perfusion. Artif Organs (2015) 39(1):53-8. doi:10.1111/aor.12455

Conflict of Interest Statement: The research was conducted in the absence of any commercial or financial relationships that could be construed as a potential conflict of interest.

Copyright (C) 2017 Beck, Loron, Masson, Poli-Merol, Guyot, Guillot, Bednarek and François. This is an open-access article distributed under the terms of the Creative Commons Attribution License (CC BY). The use, distribution or reproduction in other forums is permitted, provided the original author(s) or licensor are credited and that the original publication in this journal is cited, in accordance with accepted academic practice. No use, distribution or reproduction is permitted which does not comply with these terms. 